\title{
REVIEW
}

Open Access

\section{The reversal of human phylogeny: Homo left Africa as erectus, came back as sapiens sapiens}

Úlfur Árnason ${ }^{1 *}$ and Björn Hallström²

\begin{abstract}
Background: The molecular out of Africa hypothesis, OOAH, has been considered as an established fact amid population geneticists for some 25-30 years despite the early concern with it among phylogeneticists with experience beyond that of Homo. The palaeontological support for the hypothesis is also questionable, a circumstance that in the light of expanding Eurasian palaeontological knowledge has become accentuated through the last decades.
\end{abstract}

Results: The direction of evolution in the phylogenetic tree of modern humans (Homo sapiens sapiens, Hss) was established inter alia by applying progressive phylogenetic analysis to an mtDNA sampling that included a Eurasian, Lund, and the African Mbuti, San and Yoruba. The examination identified the African populations as paraphyletic, thereby compromising the OOAH. The finding, which was consistent with the out of Eurasia hypothesis, OOEH, was corroborated by the mtDNA introgression from Hss into Hsnn (Neanderthals) that demonstrated the temporal and physical Eurasian coexistence of the two lineages. The results are consistent with the palaeontologically established presence of $H$. erectus in Eurasia, a Eurasian divergence between $H$. sapiens and $H$. antecessor $\approx 850,000 \mathrm{YBP}$, an $\mathrm{Hs}$ divergence between Hss and Hsn (Neanderthals + Denisovans) $\approx 800,000$ YBP, an mtDNA introgression from Hss into Hsnn* $\approx 500,000$ YBP and an Eurasian divergence among the ancestors of extant Hss $\approx 250,000$ YBP at the exodus of Mbuti/San into Africa.

Conclusions: The present study showed that Eurasia was not the receiver but the donor in Hss evolution. The findings that Homo left Africa as erectus and returned as sapiens sapiens constitute a change in the understanding of $\mathrm{Hs}$ evolution to one that conforms to the extensive Eurasian record of $\mathrm{Hs}$ palaeontology and archaeology.

Keywords: Human evolution, Molecular phylogenetics, Progressive phylogenetic analysis, PPA, Palaeontology, Out of Eurasia hypothesis, OOEH, Out of Africa hypothesis, OOAH, mtDNA, nuDNA

\footnotetext{
* Correspondence: ulfur.arnason@med.lu.se; ulfur.arnason@gmail.com

The present work is dedicated to the memory of Professor Albert Levan $(8 / 3$ $1905-28 / 3$ 1998). It was in his laboratory at the Institute of Genetics, Lund that the correct chromosome number of man, $2 n=46$, was determined. For more than 40 years prior to that demonstration, the reiterated belief was that man had 48 chromosomes.

'Department of Brain Surgery, Faculty of Medicine, University of Lund, Lund, Sweden

Full list of author information is available at the end of the article
}

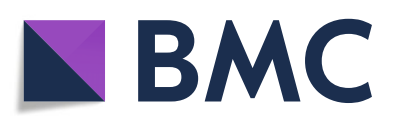

(- The Author(s). 2020 Open Access This article is licensed under a Creative Commons Attribution 4.0 International License, which permits use, sharing, adaptation, distribution and reproduction in any medium or format, as long as you give appropriate credit to the original author(s) and the source, provide a link to the Creative Commons licence, and indicate if changes were made. The images or other third party material in this article are included in the article's Creative Commons licence, unless indicated otherwise in a credit line to the material. If material is not included in the article's Creative Commons licence and your intended use is not permitted by statutory regulation or exceeds the permitted use, you will need to obtain permission directly from the copyright holder. To view a copy of this licence, visit http://creativecommons.org/licenses/by/4.0/. The Creative Commons Public Domain Dedication waiver (http://creativecommons.org/publicdomain/zero/1.0/) applies to the data made available in this article, unless otherwise stated in a credit line to the data. 


\section{Background}

Two molecular studies $[1,2]$ that came from the same laboratory were highly instrumental in the promotion of the out of Africa hypothesis, OOAH, $\approx 30$ years ago. The hypothesis became gradually a mainstay in the discussion of human evolution and dispersal in spite of the absence of palaeontological support for it and the circumstance that reanalysis of the data [3-5] did not favour the phylogenies that constituted the foundation for the OOAH.

The OOAH was addressed previously in two studies $[6,7]$ in which the author maintained on the basis of molecular and palaeontological data that recent humans, Hss, had originated in Eurasia (the Out of Eurasia ypothesis, OOEH) and dispersed from there to other parts of the world including Africa. In the present study the two hypotheses were compared in the light of the identity of the basal divergence of the Hss tree as established in genomic analyses [8,9]. One of these studies [8, Fig. 2a; see also 7, Table 1] identified this divergence as falling between all non-Africans and the African branch of Mbuti/San. The results of the other study [9], which included the Baka population as a representative of basal African lineages and Koinabe (Sahul) as a representative of non-Africans, complied with that finding. The implications of the results were detailed in a previous examination of OOAH and OOEH [7]. As concluded there the reorientation of the Hss tree was inconsistent with the understanding that the ancestors of non-Africans had originated by an exodus out of Africa.

The steady progress in the molecular analyses of Hss and Hsn (Hsnn + Hsnd) [10-17] has allowed an extended examination of OOAH and OOEH. With the palaeontology of $H s n(H s n n+H s n d)$ strictly limited to Eurasia [18-21] the molecular exchanges between Hss and $H s n$ are consistent with a continuous existence in Eurasia of an Hss population that is much older than the basal divergence among extant Hss populations, i.e. that between non-Africans and Mbuti/San. The palaeontological support for OOEH is upheld similarly by the findings of Eurasian Hss fossils [e.g. 22] whose ages, $\approx$ 200,000 years, surpass by $130,000-140,000$ years the age that is commonly associated with the dispersal of Hss out of Africa. These finds and the Eurasian placement of the root of the Hss tree constitute a natural extension of the extensive Eurasian, palaeontological and archaeological records that relate to the origin and evolution of Hss and Hsn [23-72]. The existence and hence the phylogenetic implications of these studies have remained disregarded, however, among the proponents of OOAH.

Here the Out of Africa and the Out of Eurasia hypotheses were compared inter alia in the light of a new approach, progressive phylogenetic analysis (PPA), that allowed the examination of the mtDNA relationship among the African Hss populations in the light of new palaeontological and molecular findings. The particular result of this examination was that it disrupted the monophyly of the African populations, therewith compromising the cornerstone of OOAH.

\section{Results and discussion}

\section{The OOEH phylogeny of basal Hss relationships}

The essence of the nuDNA phylogeny behind OOEH and the evolution of $H s(H s s+H s n)$ is shown in Fig. 1 with the Eurasian lineages marked blue and the African red. The phylogeny encompasses an African exodus of $H$. erectus $>2$ MYBP and a continuous evolution of $H$. erectus in Eurasia leading to a population that diverged into $H$. antecessor $[66,73]$ and $H$. sapiens $\approx 850,000$ YBP. The arrowheads that lead from Hss into the Hsnn* branch in Fig. 1 have a particular phylogenetic significance for the interpretation of $H s$ evolution as they signify the mtDNA introgression that took place from $H s s$ into $H s n n^{*} \approx 500,000 \mathrm{YBP}$, a transfer that could only come about in agreement with the physical coexistence of Hss and Hsnn*. In the light of the limitation of Hsnn to Eurasia the introgression and the continuous evolution of both Hss and Hsn can only be placed in this continent in accordance with OOEH.

Figure 2 summarizes the relationships connected to the evolution of $H s(H s s+H s n)$ as established in analysis of complete mtDNAs. Tree $2 \mathrm{a}$ demonstrates the basal phylogeny of the sampling, while the trees $2 \mathrm{~b}-\mathrm{d}$ show only the Hss part of the complete $H s$ tree. The analysis was restricted to the minimum number of taxa required for the examination: a chimpanzee, Pan troglodytes [74] for rooting the tree, a Neanderthal proper, Hsnn [75], a Denisovan, Hsnd [76], Mbuti, San and a series of Yoruba (all African) and Lund, the first described non-chimaeric human mtDNA sequence [74], as a representative of non-Africans. The inclusion of the Yoruba individuals rested upon the circumstance that Yoruba is commonly taken as the African ancestor of non-African populations in studies that acknowledge OOAH [e.g. 77].

Tree 2a shows the phylogeny connected to the arrowhead-marked mtDNA introgression that took place from Hss into Hsnn as shown in Fig. 1. The introgression, which gave rise to the $H s n n^{*}$ branch in $2 \mathrm{a}$, upsets the agreement between the nuDNA and mtDNA trees by joining $H s n n^{*}$ to the $H s s$ branch in the mtDNA tree, therewith disrupting the initial mtDNA relationship between $\mathrm{Hsnn}^{*}$ and $\mathrm{SH}-\mathrm{Hsnn}$, an individual representing a population from the Spanish site of Sima de los Huesos, Atapuerca [18-20, 62]. The phylogenetic nature of the arising Hss branch is consistent with the strict limitation of Hsnn, the mtDNA sister-group of Hss, to Eurasia [18-21] and the mtDNA introgression that took 


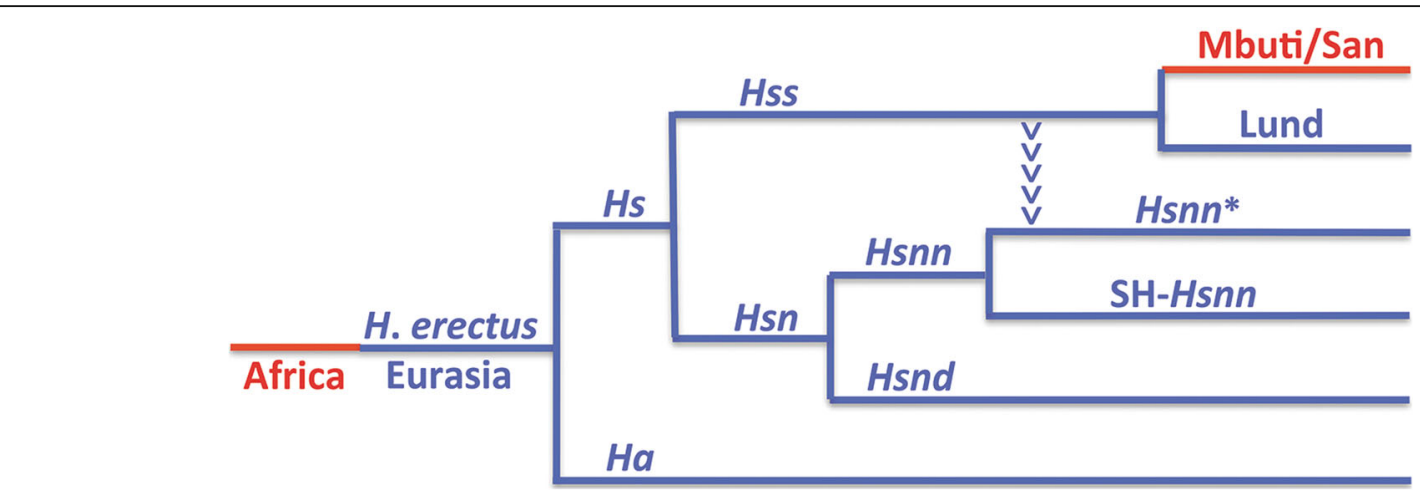

Fig. 1 The nuDNA relationship of Hs, Homo sapiens, and Ha, Homo antecessor, with Eurasian lineages in blue and African in red. Hss (H. s. sapiens); Hsn (H. s. neanderthalensis); Hsnn (H. s. n. neanderthalensis, Neanderthals proper); Hsnd (H. s. n. denisova, Denisovans). The divergence between Hs and $\mathrm{Ha}$ has been dated to $\approx 850,000$ YBP [73] and that between Hss and Hsn to $\approx 800,000$ YBP. The arrowheads mark the mtDNA introgression that took place from Hss into $H s n n^{*} \approx 500,000$ YBP, i.e. more recently than the Hsnn divergence into Hsnn* and SH-Hsnn. The basal divergence among recent Hss, as represented by the Eurasian Lund and the African Mbuti/San is placed in Eurasia at $\approx 250,000 \mathrm{YBP}$

place from $H s s$ into $H s n n^{*}$, the main branch of $H s n n, \approx$ 500,000 YBP, circumstances that are in accordance with $\mathrm{OOEH}$ at the same time as they compromise OOAH.

The Hss sampling contributing to tree $2 \mathrm{a}$ was restricted to the African Mbuti and the Eurasian Lund, two taxa that represent each of the basal lineages among extant humans. This initial representation was extended by the addition of a San and an initial Yoruba to the
PPA sampling in tree $2 \mathrm{~b}$. The extension joined San and Mbuti on a common branch while the Yoruba joined Lund on the parallel basal Hss branch. In the following PPA step, 2c, the remaining Yorubas were added to the sampling. These Yorubas divided between Lund and the first Yoruba, therewith underlining the separate positions of the Yorubas on the non-African (Lund) branch and the paraphyly of the African Hss populations.
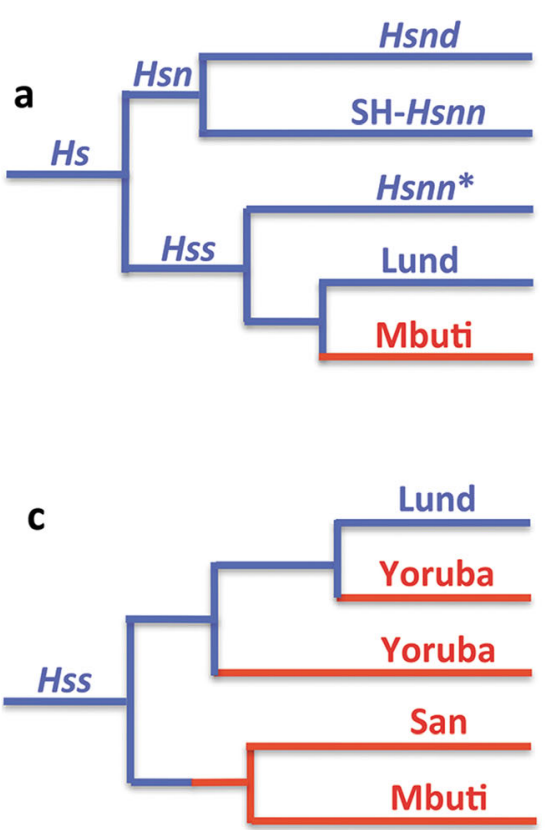
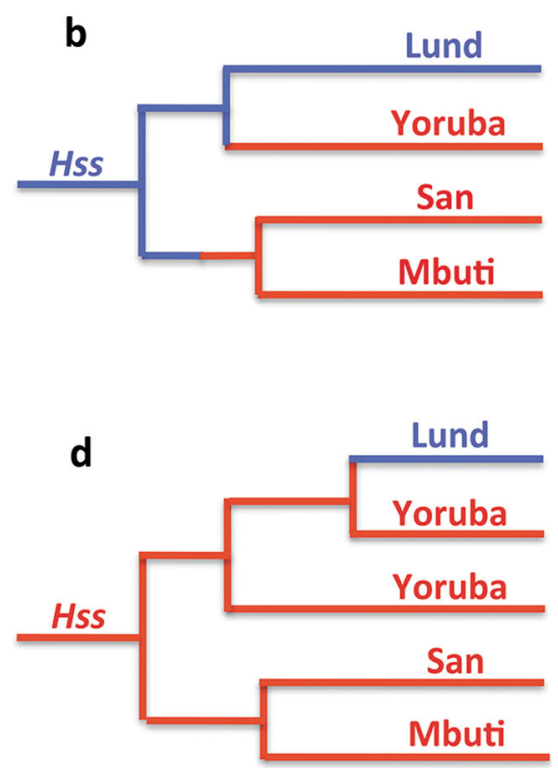

Fig. 2 The essence of Hs mtDNA relationships as resolved in PPA (Progressive phylogenetic analysis) with Eurasian lineages in blue and African in red. a: The Hs tree, rooted with the chimpanzee, shows a basal divergence between Hsn and Hss with Hsnd and SH-Hsnn on a common branch and Hsnn* joining the Hss branch as the result of the mtDNA introgression from Hss into Hsnn* $\approx 500,000$ YBP. Mbuti and Lund make up the basal divergence among extant Hss. b and $\mathbf{c}$ : The inclusion of San and the Yorubas joined San on a common branch with Mbuti, whereas the Yorubas joined the Lund branch at separate positions in accordance with the paraphyly of the African populations. d: The OOAH tree with Hss origin in Africa followed by a late exodus into Eurasia. The OOAH phylogeny separates Lund from the evolutionary sequence of Hs and Hss shown in Fig. 1 
The tree in $2 \mathrm{~d}$ demonstrates the interpretation of Hss relationships and evolution in accordance with OOAH. As apparent this tree, with its root placed in Africa and without connection to its sister-group, Hsn (Hsnn + $H s n d)$, is refuted both phylogenetically and palaeontologically. The tree is similarly incompatible with the basal nuDNA divergence between Mbuti/San and nonAfricans $[7,8]$.

The phylogenetic signification of the difference between the nuDNA and mtDNA trees of $\mathrm{Hs}$

The tree in Fig. 1 shows the relationship of Hss and Hsn $(H s n n+H s n d)$ consistent with the nuDNA monophyly of Hss and Hsn. In the light of this relationship the divergence between $H s s$ and $H s n \approx 800,000$ YBP becomes anchored in Eurasia in accordance with the principle of Last common ancestor and the strict limitation of $H s n$ to this continent as maintained earlier $[6,7]$ and consistent with the recent $H a$ results $[66,73]$. The $H s n$ branch divides into an Hsnd branch and an Hsnn branch that splits further into SH-Hsnn [18-20, 62], and the remaining Hsnn $[11,14,15]$, labelled $H s n n^{*}$. The arrowheads in the figure mark phylogenetically the mtDNA introgression that took place from $H s s$ into $H_{s n n} n^{*}$ after the divergence between $\mathrm{SH}-H s n n$ and $H s n n^{*}$.
The mtDNA tree of $\mathrm{Hs}$, Fig. 3, differs fundamentally from the nuDNA phylogeny, Fig. 1, in that Hsnd and $\mathrm{SH}-H s n n$ have become the sole Hsn representatives on a branch (SH-Hsnn + Hsnd) that is sister to the branch that harbours both $H s s$ and $H s n n^{*}$ as the consequence of the mtDNA introgression that took place from Hss into $H_{s n n} n^{*}$ as marked in Fig. 1. The position of the introgression is consistent with a phylogeny that places the transfer after the Hsnn divergence between SH-Hsnn and $H s n n^{*}$. As phylogenetically apparent an introgression in the opposite direction, i.e. from the $H s n n^{*}$ branch into $H s s$, would join Hss and Hsnn* on a branch that was sister to SH-Hsnn.

A Pan/Homo divergence at 8 MYBP [81] places the basal mtDNA divergence in Fig. 3, i.e. that between the branch of $\left(H s s+H s n n^{*}\right)$ and that of (Hsnd + SH-Hsnn) at $\approx 800,000 \mathrm{YBP}$, the mtDNA introgression from Hss into $H s n n^{*}$ at $\approx 500,000 \mathrm{YBP}$ and the basal divergence among extant humans at $\approx 250,000$ YBP. The mtDNA introgression from $H s s$ into $H s n n^{*}$ substantiates the presence of the two lineages in the same area $\approx 300,000$ years after the divergence between $H s s$ and $H s n \approx 800$, 000 YBP. With Hsnn strictly limited to Eurasia the coexistence of Hss and Hsnn confirms the restriction of Hss to this continent $[6,7]$. These phylogenetic, geographic and palaeontological circumstances together with the

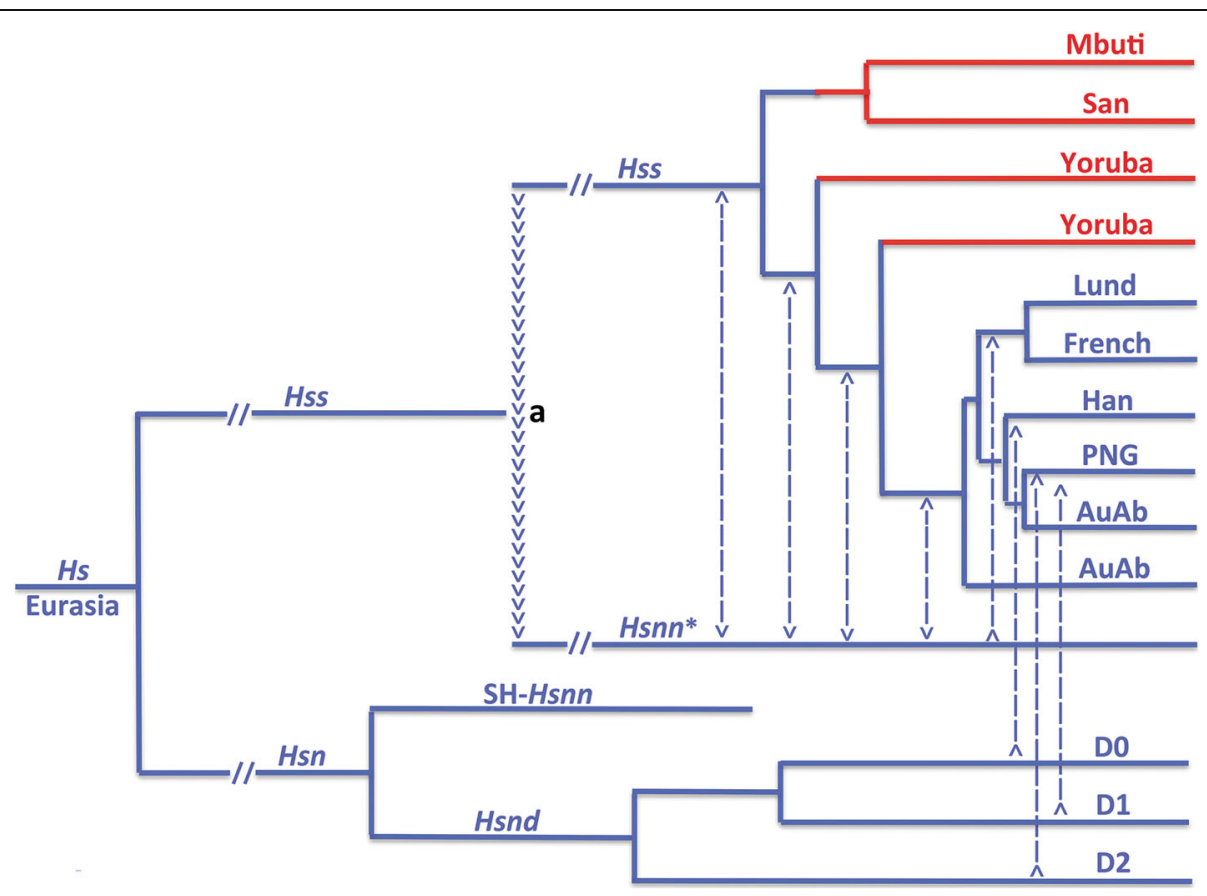

Fig. 3 Hs mtDNA relationships. Blue: non-African taxa; red: African taxa. The arrowheads (a) signify the mtDNA introgression from Hss into $H s n n^{*} \approx 500,000$ YBP, after the Hsnn divergence between Hsnn* and SH-Hsnn (see Fig. 1). The Hss phylogeny underlines the evolutionary continuity leading to the non-African populations and the paraphyly of the African populations [7]. The Hsn branch included only one Denisovan in the analysis. Dashed lines indicate general genetic exchanges [11-15] with these from D0, D1 and D2 showing specific input from separate Denisova lineages [78]. The phylogenetic relationship related to SH-Hsnn and the Denisovans is in accordance with independent findings [11, 14, 15, 76, 78-80]. AuAb: Australian aborigines; PNG: Papua New Guinean; Han: Chinese; Lund and French: Europeans 
paraphyly of the African populations as demonstrated by the PPA results and the identity of the divergence between $\mathrm{Ha}$ and $H s$ are consistent with an evolutionary scenario that anchors the divergence between Hss and $H s n$ as well as the mtDNA introgression from $H s s$ into $H_{s n n}{ }^{*}$ in Eurasia, findings that reverse the direction of Hss evolution compared to that assumed by OOAH.

The distinction between the mtDNA and nuDNA trees of Hss and Hsnn was addressed in a molecular study [15] in which the authors related the mtDNA identity of $H s n n$ to an exodus of an African Hss lineage into Eurasia and the introgression of the mtDNA of this lineage into $H s n n$, followed by an extinction of the Hss lineage. That scenario is compromised by the phylogenies shown in Figs. 1 and 3 and the extensive and continuous Eurasian palaeontology of both $H s n$ and Hss connected to these relationships [e.g. 18-26, 29-34, 38-40, 42-47, 51, 52, $56-58,60-68]$. The age and nature of the Hss fossils at Dali [29, 65], New Cave [30], Jinniushan [33] and Xujiayao [56] included in Fig. 4 are of particular interest in this respect as their ages $\approx 250,000-270,000$ years underline the Eurasian existence of $H s s$ at a time that precedes or coincides with the basal divergence among the ancestors of recent Hss.

In addition to the mtDNA introgression from Hss into $H s n n^{*} \approx 500,000$ YBP Fig. 3 marks general genetic transfers that took place between Hsn $(H s n n+H s n d)$ and different Hss populations. The Hsnd input into Papuans was addressed in a study [78] that rested upon OOAH and an African Hss exodus 64,000 YBP, conclusions that differ from the extension of Eurasian palaeontology. The analysis identified two Hsnd introgressions into Papuans,

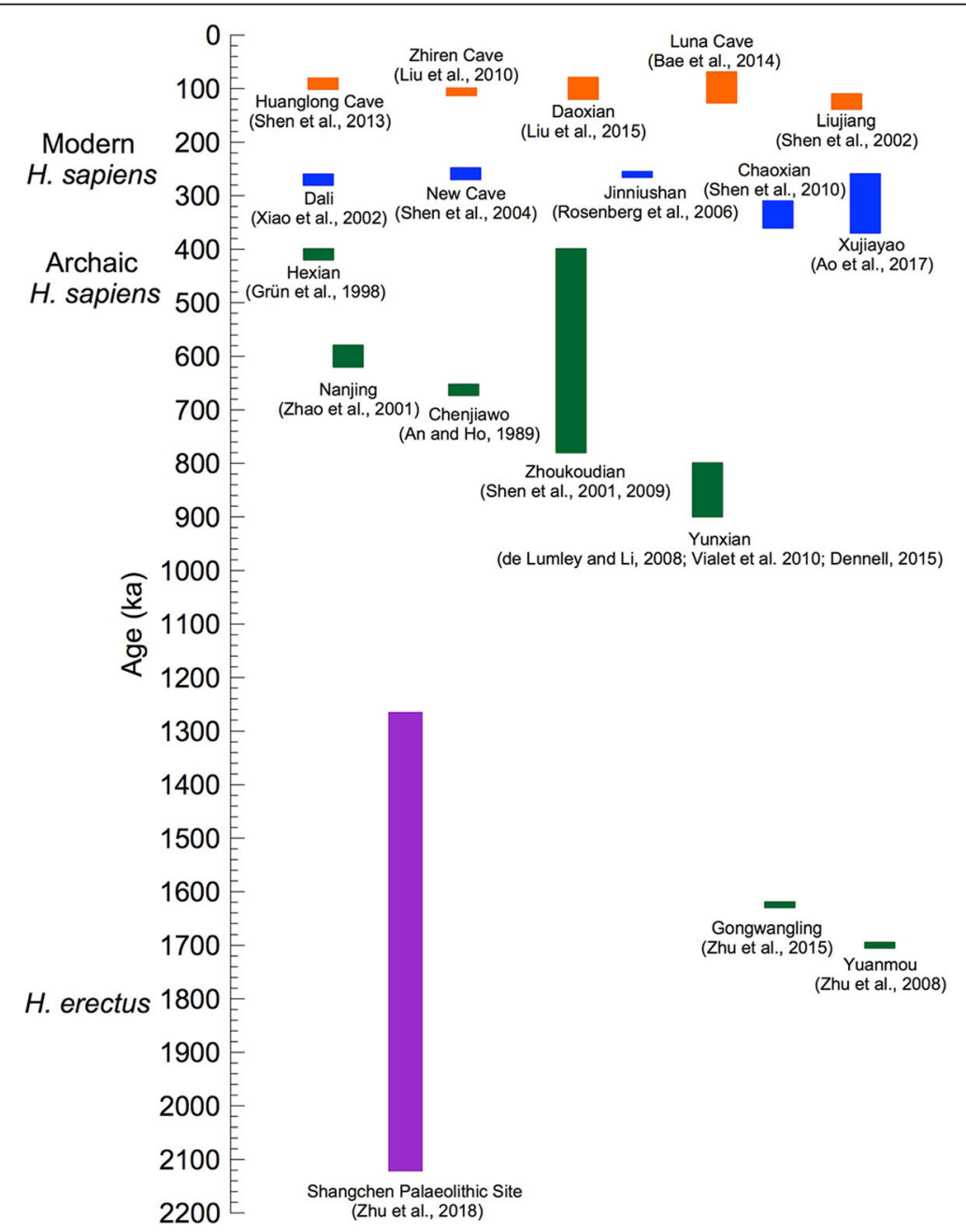

Fig. 4 An overview of Chinese palaeontological and archaeological sites related to Hs evolution. The Palaeolithic locality at Shangchen (violet) spans the period from 2,12 to 1,26 MYBP. The Yunxian and Zhoukoudian samplings overlap temporally the divergence into $H$. antecessor and $H$. sapiens $\approx 850,000$ and $H s s$ and $H s n \approx 800,000$ YBP, making room for that the two lineages arose from a common Eurasian population of $H$. erectus. The blue section shows more recent Hss positions allowing for admixing with $H s n(H s n n+H s n d)$. The same section covers the interval preceding the divergence between Eurasians and Mbuti/San $\approx 250,000$ YBP. The Hualongdong fossils [70], discussed in the text, constitute a part of the blue section. The figure has been adapted and extended from Fig. 10 [56], by permission of the authors 
one (D2) at 46,000 YBP the other (D1) at 30,000 YBP. According to the study the D1 branch had split from the Altai Denisovan $\approx 283,000 \mathrm{YBP}$ and the D2 branch $\approx$ 363,000 YBP. The authors maintained that the D2 estimate was close to that of the divergence between Hsnn and Hsnd, an underestimate of that particular divergence.

With respect to the basal Hss divergence among extant humans there is a fundamental phylogenetic discrepancy between Figs. 1, 2 and 3 and the initial studies advocating OOAH $[1,2]$, which were based on fragmentary mtDNA data. Reanalysis [3] of the data set behind the first study [1] showed that there were thousands of trees that were better by five steps or more than the tree that constituted the basis of the OOAH argument. The terminology used in the study was also inconclusive as the terms "Europa" and "Caucasians" encompassed Europa proper, North Africa and the Middle East (unspecified). Thus, Africa referred only to a part of this continent, compromising the assumption that "Assuming that Africa is the source, there is only one African cluster". The phylogenetic problems emerged also in the joining of the HeLa lineage (Afro-American) with one Asian, one Australian Aborigine and one European. Similarly, the composite Cambridge mtDNA sequence [82], with its Afro-American HeLa component, grouped among "Europeans".

The follow-up study [2] from the same laboratory was limited to parts of the mtDNA control region. The authors maintained that the analysis had yielded the same pattern as the previous study [1] and that the identification of 14 sequential basal African branches provided the strongest support yet for the placement of the human mtDNA ancestor in Africa. As in the case of the first study a reanalysis of the data $[4,5]$ identified large numbers of trees that were more parsimonious than the tree that the authors [2] presented and based their $\mathrm{OOAH}$ reasoning.

\section{OOEH and OOAH in the light of palaeontology}

The fossil record of Hss is commonly interpreted in compliance with the preconceptions of OOAH in the discussion of $H s s$ evolution. The characterization of the African fossils has a notably wide span, ranging from "The fossil evidence for an African origin for modern humans is robust" [83] to "The hominin fossil record of the African Middle Pleistocene is extremely sparse" [84]. The latter and more inclusive study also detailed that the African fossils were missing adequate provenance in most cases (see Table 1 and Fig. 1 of the study), with the possible exception of the South African Florisbad skull and the age, 260,000 +/-35,000 years, of the tooth associated with it [85]. Furthermore, Africa contains no fossils of $H s n$ the mtDNA sister group of Hss, a crucial phylogenetic circumstance as underlined previously $[6,7]$. In comparison the limitation of Hsn to Eurasia and the genetic exchanges between $H s n$ and Hss provide fundamental palaeontological and molecular results that are consistent with the origin and continuous existence of Hss in Eurasia, in accordance with the phylogenies in Figs. 1, 2 and 3.

With respect to the palaeontology and archaeology related to Hss evolution it of particular interest to consider the Eurasian advances in this field during the last $20-25$ years. The early stages of the progress were discussed in a study [31] that related the morphological skull mosaic between $H s s$ and $H$. erectus to a continuous $H s$ admixing in Asia, including gene flow between eastern and more westerly Asia. As regards the morphological distinction between sapiens and erectus the author [31] recognized them as subspecies, Homo sapiens sapiens and Homo sapiens erectus, in accordance with their overlapping morphology.

The expansion of Eurasian palaeontology has provided insight into the interwoven evolution of $H$. erectus and Hss in Eastern Eurasia [e.g. 23, 26, 29-31, 33, 40, 41, 45, $50,51,56,61,63,64,67,69,86]$. One of these studies [56] included a figure, modified here as Fig. 4, which showed the chronostratigraphy among a number of Chinese sites that encompassed $H$. erectus, archaic and modern Hss and potential Hsnn and Hsnd. The temporal span of the palaeontological findings extended from 1.7 MYBP to 60,000 YBP. The palaeontological and archaeological site at Xujiayao, which was the primary subject of the study [56], covered the period from $\approx 370,000$ YBP to $\approx 250,000$ YBP, i.e. a substantial part of $H s s$ evolution prior to the Hss divergence between Mbuti/San and the branch of other extant humans as shown in Figs. 1, 2 and 3. The Xujiayao site belongs to the particular temporal span (blue) that extends from $\approx 380,000$ YBP to $\approx$ 220,000 YBP in Fig. 4, which the authors [56] related to the late coexistence and genetic admixture of $H$. erectus and early $H s s$ plus an $H s n$ input from potentially both Hsnn and Hsnd. It should be noted that the latter part of this timespan coincides with the genetic exchanges that have been recorded between Hsnn and Hss before the basal divergence among recent humans [12, 13, 15-17].

The early part of the time range of Xujiayao coincides temporally with the Chaoxian site [40] while the more recent range of the site overlaps with the age of the sites at Dali [29, 65], New Cave [30], Jinniushan [33] and Hualongdong [70], which also provide palaeontological evidence for an extended $H s n / H s s$ interface in Eurasia preceding the basal Hss divergence between the ancestors of Mbuti/San and remaining Hss populations shown in Figs. 1, 2 and 3. Regarding the volume of the samples from the Xujiayao site it may be noted that they have, in addition to 20 fossil human specimens, yielded more 
than 30,000 lithic artefacts and about 5000 mammalian fossils that substantiate the nature and age and of the human specimens.

With respect to the age, 1,7 MY, of the Yuanmou finds [36] and that of 1,63 MY of the Gongwangling samples [54] in Fig. 4 it is of crucial interest that their age became exceeded by a wide margin by the artefact sequence from Shangchen, near the Gongwangling site [68]. The 17 continuous artefact layers studied covered a timespan from 2,12 MYBP to 1,26 MYBP. The authors concluded that the findings were in accordance with hominins leaving Africa considerable earlier than indicated by the age, 1,77-1, $85 \mathrm{MY}$, of the Homo erectus fossils from the Georgian Dmanisi site $[87,88]$. The easterly range of $H$. erectus is represented by the younger Indonesian distribution of the taxon [89-91].

Archaeological sites east of the Mediterranean Sea have revealed a human presence as early as 400,000 YBP $[25,38]$. The fossils were not assigned specifically to either Hss or Hsn, however. In comparison, the human fossils from Qafzeh and Skhul with an age of 90,000100,000 years were identified as distinct $H s s$ [23, 26]. These fossils together with later described Hss fossils from the same region, with an age of 180,000-200,000 years [22] fall into the western part of the Eurasian $H s s$ distribution that corresponds to the span of modern $H$. sapiens in Fig. 4, i.e. Hss after the divergence between Mbuti/San and the remaining Eurasian populations.

The African palaeontology related to $H s$ origin and evolution is distinctly poorer than that of Eurasia. The African Homo picture outside Hss became extended significantly, however, with the description of the fossils of $H$. naledi, which comprise by far the largest assemblage of Homo fossils in Africa. The fossils come from two sites in the South African Rising Star cave system, the Dinaledi Chamber and the Lesedi Chamber [84, 92]. Neither site contains other Homo fossils. Dating of the Dinaledi fossils constrains their age to 236,000-335,000 YBP. Another estimate based on the two least-altered naledi teeth found yielded a maximum average age of $253+82 /-70$ thousand years and a minimum average age of $200+70 /-61$ thousand years [93].

The extensiveness of the $H$. naledi fossils is notable compared to the scarcity of Hss fossils in a region that according to proponents of OOAH may have constituted the cradle of Hss. Another circumstance relates to the question how $H s s$ and $H$. naledi, which might have shared similar ecological niches, could thrive contemporaneously in the same area. Taken together the findings allow the proposal that naledi evolved in southern Africa without competition from $H s s$ and that it was a later intrusion of $H s s$ from the north that led to the demise of $H$. naledi. In this case the Florisbad fossil would constitute a representative of early $H s s$ intruders (possibly Mbuti/San) coming from the north.

The redating of the fossils at the Jebel Irhoud site, Morocco [94, 95], which increased their age by $\approx 100$, 000 years compared to an earlier study of the same site [96], renders the fossils of interest for the discussion of Hss evolution in the light of the deepest divergence among recent humans, $\approx 250,000 \mathrm{YBP}$, and the reversal of the direction of evolution of the $H s$ tree as discussed in connection with Figs. 1, 2 and 3. The age of the tooth examined was $286+/-32$ thousand years, somewhat younger than the age, $315+/-34$ thousand years, of the artifacts connected to layer $7[94,95]$. The finds have particular implications in the light of the Chinese finds of Dali, New Cave, Jinniushan, Xujiayao and Hualongdong, blue in Fig. 4, which fall in the same part of the temporal interval between the mtDNA introgression from Hss into $H s n n^{*} \approx 500,000$ YBP and the basal divergence among recent $H s s \approx$ 250,000 YBP. As the revised age of the Jebel Irhoud fossils exceeds by some margin the age of the basal divergence among extant humans it appears that the Jebel Irhoud population became extinct without contributing to the genetic constitution of extant Africans.

A recent study [97] of the Greek palaeontological finds Apidima 1 and Apidima 2 characterized the Apidima 1 fossil with an allocated age of $\approx 210,000$ years as constituting the earliest known presence of Homo sapiens (Hss here) in Eurasia. This conclusion is implausible considering both the calculation of the age of the Apidima 1 fossil $[71,98]$ and the large series of much older Eurasian palaeontological finds related to Hss evolution that had escaped the attention of the authors [97]. A similar disregard of Eurasian palaeontology appeared in a preceding study [99] that detailed a scenario that rested upon an African origin and divergence between Neanderthals and Denisovans $\approx 480,000$ YBP and their exodus into Eurasia $\approx 400,000$ followed by an Out of Africa dispersal of modern humans $\approx 75,000-125,000$ YBP, circumstances that are incompatible with the extensive Eurasian palaeontology of both $H s n$ and Hss and molecular findings, including the molecular exchanges between $H s s$ and Hsn $(H s n n+H s n d)$. Similarly, a more comprehensive study [100] that appeared in the same journal did not allow a treatment of the Eurasian palaeontology related to Hss origin and dispersal as the discussion rested upon OOAH and a temporal demarcation at 125,000 YBP for the oldest Eurasian fossils discussed in the context of Hss evolution.

\section{The OOEH synthesis}

The present reorientation of the $H s$ tree in conjunction with the palaeontology of $H$. erectus makes the period 
$\geq 900,000$ to 500,000 YBP highly significant for the discussion of $H s$ evolution as it covers both the advent and sequel of the divergences that encompass $H$. erectus, $H$. antecessor, Hss and Hsn (Hsnn + Hsnd) shown in Fig. 1.

The Asian phase of $H$. erectus evolution $\geq 900,000$ YBP is exemplified in Fig. 4 by the Chinese site at Yunxian $[35,41,53,56]$ and the age, 936,000 years, of the best-preserved scull (Yunxian II) excavated at this site [35, 41]. With regard to the Yunxian II specimen one of these studies [41] concluded that the facial features of the fossil displayed a pattern close to modern humans and that the assignment of the scull to $H$. erectus extended the variability connected to this species. In this light and in recognition of the fossil record of $H$. erectus the findings are consistent with the origin of a branch that arose within a diversifying Asian $H$. erectus population which diverged into the westward going population of $H$. antecessor, which came to reside for a short period in SW Europa, and another population, $H$. sapiens, that split later into Hss and Hsn. According to this understanding $H s n$ diverged further into Hsnd and Hsnn with Hsnd diversifying essentially in eastern Asia and the
Sahul and Hsnn inhabiting a large Eurasian area within which it diversified into a westerly branch, $\mathrm{SH}_{-}$ $H s n n$, and a more widely spread population, $H s n n^{*}$, characterized by the mtDNA introgression from $\mathrm{Hss}$ $\approx 500,000$ YBP, a circumstance that manifests the lasting and contemporary Eurasian presence of Hss and Hsnn.

It should be noted that the Hss part of the mtDNA tree in Fig. 3 suggests that the Eurasian Hss population went through a severe bottleneck prior to the diversification shown in the figure. In comparison the African population structure suggests that the populations arising from the different Hss exoduses into Africa remained relatively unaffected in this respect.

\section{Hss evolution in relation to climatic changes}

The estimated ages of the divergences related to Hss and $H s n$ show considerable variation among authors depending on the calibration points chosen. In the present study we have applied as a calibration point the Homo/Pan divergence set at $8 \mathrm{MYBP}$, in accordance with the mammalian calibration point A/C-60 [81]. As mentioned above the $8 \mathrm{MY}$ age of the

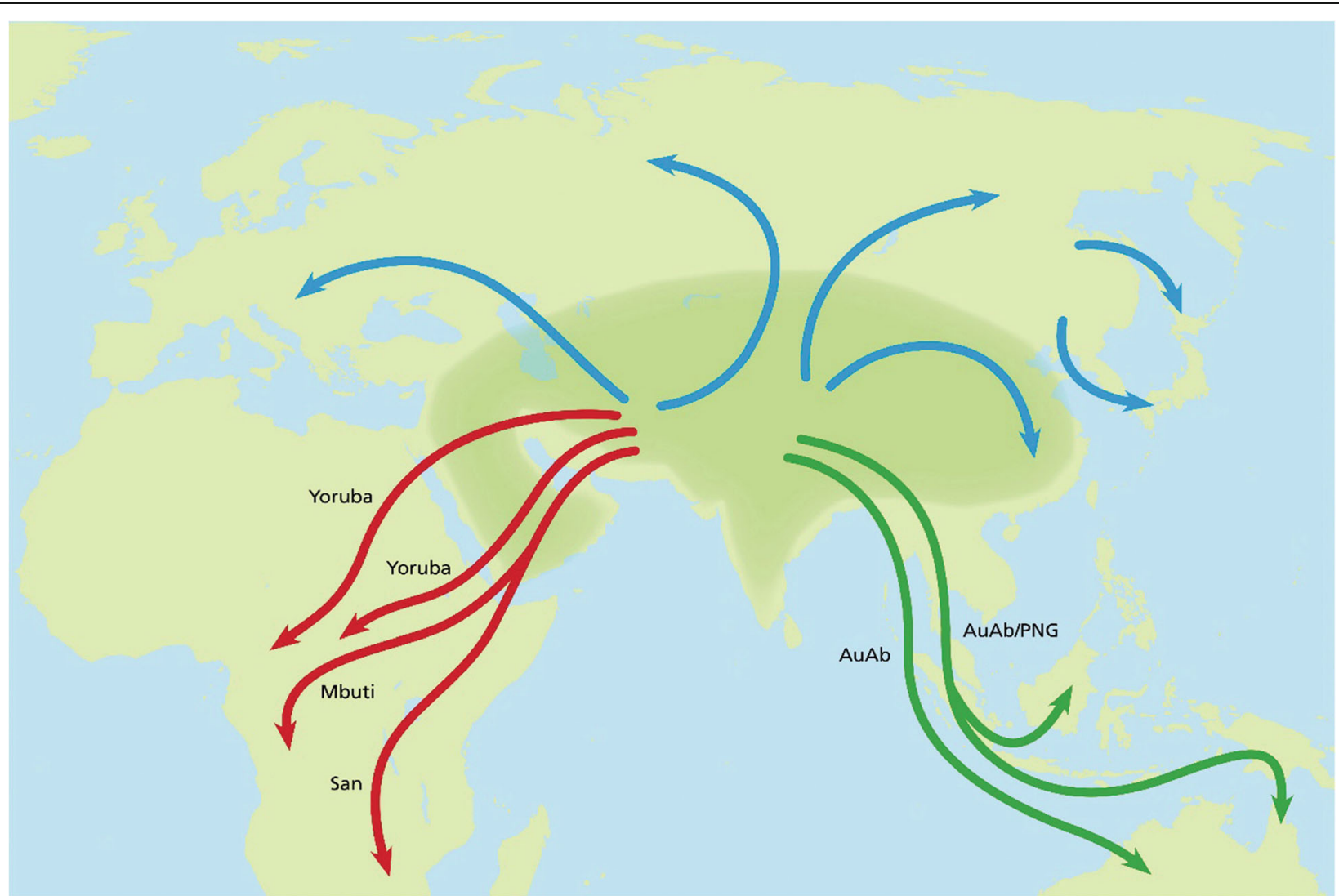

Fig. 5 A simplified view of Hss dispersal. The shaded area signifies a geographically undefined Asian (Eurasian) area from which Hss dispersed. Mbuti/San mark the earliest Hss exodus into Africa followed by later Yoruba exoduses. The green tracks represent routes that signify potential routes into Southeast Asia and Oceania 
Homo/Pan divergence places the basal $H s$ divergence between $H s s$ and $H s n$ at $\approx 800,000$ YBP and the mtDNA introgression from $H s s$ into $H s n n^{*}$ at $\approx 500$, 000 YBP. Within the Hss lineage itself the basal divergence, that between Mbuti/San and other recent lineages, becomes placed at $\approx 250,000 \mathrm{YBP}$, the time of the two Yoruba exoduses into Africa at $\approx 225,000$ and $\approx 180,000$ YBP respectively and the age of the basal divergence among recent non-Africans at $\approx 125$, 000 YBP. The ages of three of these estimates, $\approx 250$, $000, \approx 225,000$ and $\approx 125,000 \mathrm{YBP}$, coincide with warm global temperatures that were preceded by low maxima as recorded in analyses of Antarctic ice core records [101-103]. The picture is consistent with a Eurasian $H s s$ population that passed three cold-related bottlenecks, each of which was followed by population expansion and concomitant dispersal. Although the coincidence between the timings of the molecular estimates and climatic changes might not be absolute they underline the scenario of oscillating climatic conditions that are likely to have affected vegetation and population structures among both humans and their prey in connection with changes in sea levels and routes of dispersal.

The molecular variation within Africa in both mtDNA [104] and nuDNA [8] is greater than that among nonAfrican populations. Among population geneticists this variation has been commonly interpreted as supporting OOAH without considering the phylogenetic nature of the relationships connected to the different $H s$ divergences leading to recent humans. The identity of these relationships as maintained here and the paraphyly of the African populations suggests a different explanation, namely that the African variation is the effect of consecutive Hss dispersals from Eurasia into Africa and climate-related Eurasian Hss bottlenecks that reduced the non-African variation, the most distinct being that ending $\approx 125,000$ YBP. A scenario of this kind concurs with climate history and the glaciation cycles discussed above [101-103]. It has been noted similarly in several studies [17, 105-107] that the amount of Hsnn DNA in African genomes is less than that of non-Africans, a finding that is consistent with the African absence of both Neanderthals and Denisovans and an extended contact by Neanderthals and Denisovans with the nonAfrican populations.

Figure 5 shows potential routes related to the dispersal of Hss in accordance with the PPA findings and the relationships behind Figs. 1, 2 and 3. The depicted routes allow ample room for the genetic exchanges between Hss and Hsnn and Hss and Hsnd in Eurasia and more south-easterly regions that have been detailed in a series of nuDNA studies [e.g. 10, 12, 13, 15-17, 80, 81, 108-111].

\section{Conclusions}

The reversal of the direction of evolution in the tree of Homo sapiens sapiens is consistent with the molecular identification of the sister group relationship between $H$. sapiens and $H$. antecessor and a Eurasian separation into $H$. antecessor and H. sapiens $(H s s+H s n) \approx 850.000 \mathrm{YBP}$ $[66,73]$ within a diversifying population of $H$. erectus. The hitherto earliest recorded phase of hominin presence in Eurasia, that at Shangchen, China, has been dated to $\approx 2.1$ MYBP [68]. The finds constitute a temporal extension of the palaeontological findings of $H$. erectus in Dmanisi, Georgia, $\geq 1.8$ MYBP $[87,88]$ and Yuanmou, China, 1.7 MYBP [36] and a series of younger finds that underline the Eurasian existence of $H$. erectus preceding the divergence between $H$. antecessor and $H$. sapiens.

We postulate that following the separation between $H$. sapiens and $H$. antecessor $\approx 850.000, H$ s diverged further into $H s s$ and $H s n \approx 800.000$ YBP. The Eurasian continuity of these two lineages is underlined by the molecular diversity of Hsnn and Hsnd and the mtDNA introgression that took place from $H s s$ into $H s n n^{*} \approx 500,000$ YBP. In comparison the Hss branch remains undivided until the basal divergence among the ancestors of extant Hss as represented in Fig. 1 by Lund and the African populations of Mbuti/ San, therewith bringing to an end the evolutionary journey that began by Homo erectus leaving Africa $\geq 2$ million years earlier.

\section{Appendix}

OOAH has been assumed as a phylogenetic fact for some 30 years in the molecular discussion of $H s$ (Hss + $H s n(H s n n+H s n d))$ evolution in spite of the absence of palaeontological support for the hypothesis. A concerning circumstance related to the hypothesis is that the initial mtDNA studies $[1,2]$ reported phylogenies that were inconsistent with a large series of better trees [3-5], a condition that compromised the phylogenetic conclusions of both studies. Unfortunately, the authors [1, 2] did not clarify or respond to this crucial issue, therewith promoting the impression that the criticism [3-5] was unsubstantiated.

The survival of OOAH draws attention to a particular case at the Institute of Genetics, University of Lund, our previous premises, that terminated the long-lasting belief in the erroneous human chromosome number, $2 n=48$. The case relates to the establishment of the human karyotype and the correct chromosome number, $2 n=46$, under the auspices of Prof. Albert Levan [112] as detailed at the 50 year anniversary of the findings [113]. The study in question [112] rested upon the introduction of three essential cytogenetic legs, viz. the use of cell cultures 


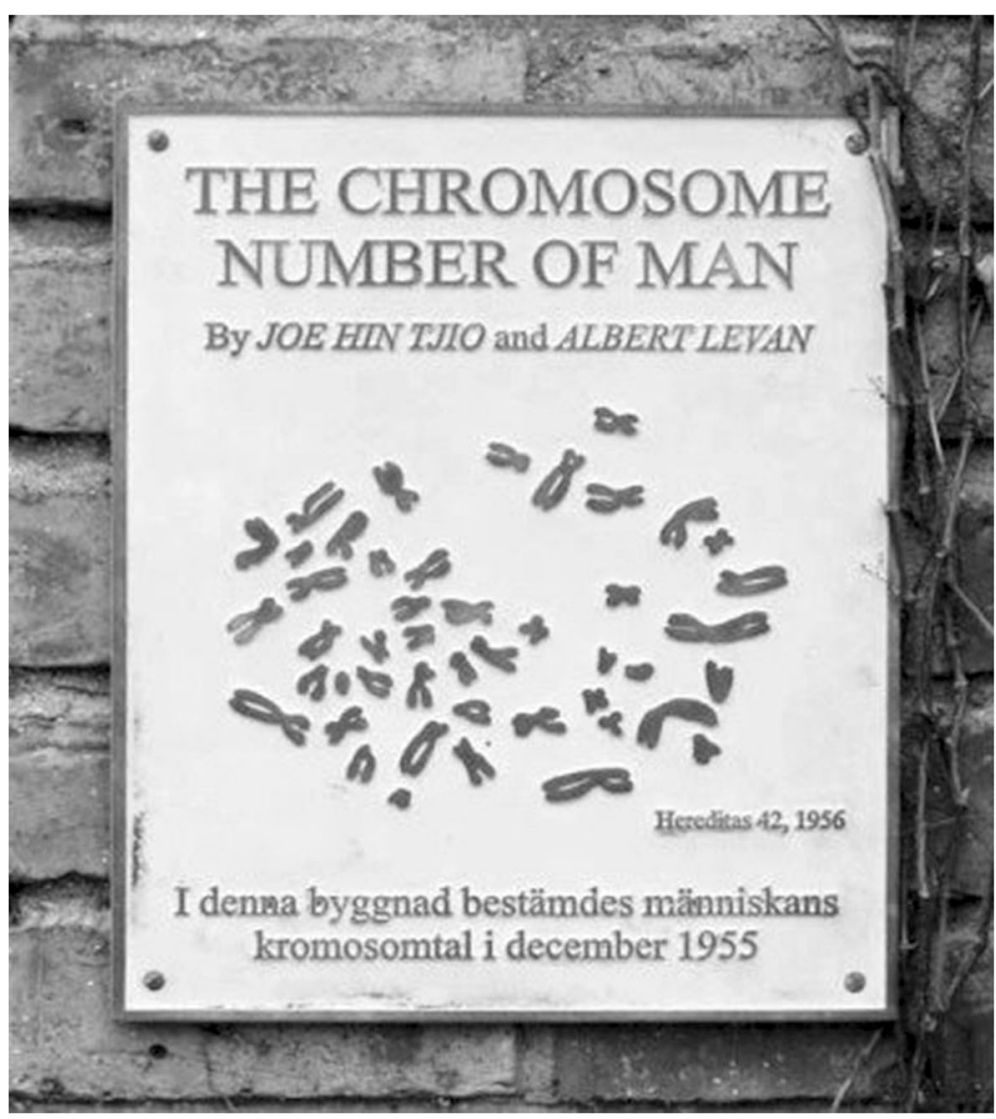

Fig. 6 The no longer extant copper plate commemorating the establishment of the $2 n=46$ chromosome number of man at the Institute of Genetics, University of Lund, Sweden

(delivered by Dr. Rune Grubb providing dividing single cells), the application of colchicine (for constricting the chromosomes and arresting the cells in metaphase), and hypotonic treatment (for the swelling of the cells prior to fixation). The work [112] paved the way for an explosive expansion of cytogenetics at the same time as it dispelled an understanding that had reigned for more than 40 years with the last $2 n=$ 48 count becoming that by Prof. C. D. Darlington and his collaborator who reported this number in two males [114].

In 2006, at the 50 years anniversary of the study of Tjio and Levan [112], there appeared a few accounts that presented diverging details related to the establishment of the $2 n=46$ number. The major discrepancies among these descriptions could be resolved, however, by the fortunate finding of the logbook of Levan's laboratory [113].

A copper plate, Fig. 6, commemorating the establishment of the $2 n=46$ human karyotype was uncovered at the Institute of Genetics on March 8th, 2003, on the 100th birthday of Karin Levan, Albert Levan's wife. The title of the paper, the names of the authors and the incorporated metaphase are replicates from the original publication [112]. The Swedish text reads in translation: "The chromosome number of man was determined in this building in December 1955". The plate became stolen later. It has not been replaced and the discovery has fallen into oblivion.

\section{Abbreviations}

Ha: Homo antecessor; He: Homo erectus; Hs: Homo sapiens; Hss: Homo sapiens sapiens; Hsn: Homo sapiens neanderthalensis (Neanderthals + Denisovans); Hsnn: Neanderthals proper; SH-Hsnn: Neanderthals from the Spanish site of Sima de los Huesos representing a branch that evolved without the introgression of Hss mtDNA; Hsnn*: Neanderthals characterized by the mtDNA introgression from Hss; Hsnd: Denisovans

\section{Acknowledgments}

We thank Profs Eric H. Harley, Cape Town, RSA; Takashi Gojobori, Thuwai, Kingdom of Saudi Arabia; Ed Southern, Oxford, England; Axel Janke, Frankfurt am Main, Germany; Hong Ao, Shaanxi, China; Martin Pickford, Paris, France; and Rolf Elofsson, Börje Karlsson and Kent Larsson, Lund, Sweden, for valuable comments and suggestions and Mr. Johan Leide, Lund, for graphic help. We also thank The Erik Philip-Sörensens Foundation and The Royal Physiographic Society, Lund, Sweden, for supporting the work.

\section{Authors' contributions}

Ú. Á. initiated the study and wrote the paper and B. H. carried out the phylogenetic analysis. The mitochondrial DNAs used in the phylogenetic 
analysis and dating estimates were collected from public databases. The author(s) read and approved the final manuscript.

\section{Funding}

Erik Philip-Sörensen Foundation.

The Royal Physiographic Society, Lund, Sweden. Open Access funding provided by Lund University.

\section{Availability of data and materials}

The datasets generated during and/or analyzed during the current study are available from the corresponding author on reasonable request.

\section{Ethics approval and consent to participate}

Not applicable.

\section{Consent for publication}

Not applicable.

\section{Competing interests}

The authors declares that they do not have any competing interests.

\section{Author details}

${ }^{1}$ Department of Brain Surgery, Faculty of Medicine, University of Lund, Lund, Sweden. ${ }^{2}$ Center for Translational Genomics, Faculty of Medicine, University of Lund, Lund, Sweden.

\section{Received: 30 October 2020 Accepted: 27 November 2020}

Published online: 19 December 2020

\section{References}

1. Cann RL, Stoneking M, Wilson AC. Mitochondrial DNA and human evolution. Nature. 1987;325:31-6.

2. Vigilant L, Stoneking M, Harpending H, Hawkes K, Wilson AC. African populations and the evolution of human mitochondrial DNA. Science. 1991; 253:1503-7.

3. Maddison DR. African origin of human mitochondrial DNA reexamined. Syst Zool. 1991;40:355-63.

4. Templeton AR. Human origins and analysis of mitochondrial DNA sequences. Science. 1992;255:737.

5. Hedges BS, Kumar S, Tamura K, Stoneking M. Human origins and the analysis of mitochondrial DNA sequences. Science. 1992:255:737-9.

6. Árnason Ú. The out of Africa hypothesis and the ancestry of recent humans: cherchez la femme (et l'homme). Gene. 2016;585:9-12

7. Árnason Ú. A phylogenetic view of the out of Asia/Eurasia and out of Africa hypotheses in the light of recent molecular and palaeontological finds. Gene. 2017:627:473-6.

8. Mallick S, Li H, Lipson M, Mathieson I, Gymrek M, Racimo F, et al. The Simons genome diversity project: 300 genomes from 142 diverse populations. Nature. 2016;538:201-6.

9. Pagani L, Lawson DJ, Jagoda E, Mörseburg A, Eriksson A, Mitt M, et al. Genomic analyses inform on migration events during the peopling of Eurasia. Nature. 2016;538:238-42.

10. Meyer M, Kircher M, Gansauge MT, Li H, Racimo F, Mallick S, et al. A highcoverage genome sequence from an archaic Denisovan individual. Science. 2012;338:222-6

11. Meyer M, Fu Q, Aximu-Petri A, Glocke I, Nickel B, Arsuaga J-L, et al. A mitochondrial genome sequence of a hominin from Sima de los Huesos. Nature. 2014;505:403-5.

12. Prüfer K, Racimo F, Patterson F, Jay F, Sankararaman $S$, Sawyer $S$, et al. The complete genome sequence of a Neanderthal from the Altai Mountains. Nature. 2014;505:43-9.

13. Kuhlwilm M, Gronau I, Hubisz MJ, de Filippo C, Prado-Martinez J, Kircher M, et al. Ancient gene flow from early modern humans into Eastern Neanderthals. Nature. 2016:530:429-33.

14. Meyer M, Arsuaga J-L, de Filippo C, Nagel S, Aximu-Petri A, Nickel B, et al. Nuclear DNA sequences from the Middle Pleistocene Sima de los Huesos hominins. Nature. 2016;531:504-7.

15. Posth C, Wißing C, Kitagawa K, Pagani L, van Holstein L, Racimo F, et al. Deeply divergent archaic mitochondrial genome provides lower time boundary for African gene flow into Neanderthals. Nature Comm. 2017. https://doi.org/10.1038/ncomms16046.
16. Hubisz MJ, Williams AL, Siepel A. Mapping gene flow between ancient hominins through demography-aware inference of the ancestral recombination graph. bioRxiv. 2019. https://doi.org/10.1101/687368.

17. Chen L, Wolf AB, Fu W, Li L, Akey JM. Identifying and interpreting apparent Neanderthal ancestry in African individuals. Cell. 2020;180:1-11.

18. Bischoff JL, Williams RW, Rosenbauer RJ, Aranburu A, Arsuaga JL, García N, et al. High-resolution U-series dates from the Sima de los Huesos hominids yields $600+/-66$ kyrs: implications for the evolution of the early Neanderthal lineage. J Archaeol Sci. 2007;34:763-70.

19. Arsuaga JL, Martínez I, Arnold LJ, Aranburu A, Gracia-Téllez A, Sharp WD, et al. Neandertal roots: cranial and chronological evidence from Sima de los Huesos. Science. 2014;344:1358-63.

20. Arsuaga JL, Carretero J-M, Lorenzo C, Gómez-Olivencia A, Pablos A, Rodríguez $\mathrm{L}$, et al. Postcranial morphology of the middle Pleistocene humans from Sima de los Huesos, Spain. Proc Natl Acad Sci USA. 2015;112:11524-9.

21. Zanolli C, Martinón-Torres M, Bernardini F, Boschian G, Coppa A, Dreossi D, et al. The Middle Pleistocene (MIS 12) human dental remains from Fontana Ranuccio (Latium) and Visogliano (Friuli-Venezia Giulia), Italy. A comparative high resolution endostructural assessment. PLoS ONE. 2018;13(10):e0189773.

22. Hershkovitz I, Weber GW, Quam R, Duval M, Grün R, Kinsley L, et al. The earliest modern humans outside Africa. Science. 2018:359:456-9.

23. Trinkaus E. Femoral neck-shaft angles of the Quafzeh-Skhul early modern humans, and activity levels among immature near Eastern Middle Paleolithic hominids. J Hum Evol. 1993;25:393-416.

24. Bermúdez de Castro JM, Arsuaga JL, Carbonell E, Rosas A, Martínez I, Mosquera M. A Hominid from the Lower Pleistocene of Atapuerca, Spain: possible ancestor of Neandertals and modern humans. Science. 1997:276:1392-5.

25. Stiner MC, Munro ND, Surovell TA, Tchernov E, Bar-Yosef O. Paleolithic population growth pulses evidenced by small animal exploitation. Science. 1999;283:190-4.

26. Niewoehner WA. Behavioral inferences from the Skhul/Qafzeh early modern hand remains. Proc Natl Acad Sci U S A. 2001:98:2979-84.

27. Shen GJ, Ku TL, Cheng H, Edwards RL, Yuan ZX, Wang Q. High-precision Useries dating of locality 1 at Zhoukoudian, China. J Hum Evol. 2001;41:679-88.

28. Shen GJ, Wang W, Wang Q, Zhao JX, Collerson K. U-series dating of Liujiang hominid site in Guangxi, Southern China. J Hum Evol. 2002:43:817-29.

29. Xiao J, Jin CZ, Zhu YZ. Age of the fossil Dali Man in north-Central China deduced from chronostratigraphy of the loess-paleosol sequence. Quat Sci Rev. 2002;21:2191-8.

30. Shen GJ, Cheng H, Edwards RL. Mass spectrometric U-series dating of new cave at Zhoukoudian, China. J Archaeol Sci. 2004:31:337-42.

31. Wu X. 2004. On the origin of modern humans in China. Quat Int. 2004;117: $131-40$.

32. Carbonell E, Bermúdez de Castro JM, Arsuaga JL, Allue E, Bastir M, Benito A, et al. An early Pleistocene hominin from Atapuerca-TD6, Spain. Proc Natl Acad Sci USA. 2005;102:5674-8.

33. Rosenberg R, Zuné L, Ruff CB. Body size, body proportions, and encephalization in a Middle Pleistocene archaic human from northern China. Proc Natl Acad Sci U S A. 2006:103:3552-6.

34. Carbonell E, Bermúdez de Castro JM, Parés JM, Pérez-González A, CuencaBescós G, Ollé A, et al. The first hominin of Europe. Nature. 2008:452:465-9.

35. de Lumley M-A, Grimaud-Hervé D, Li T, Feng XB, Wang Z. Les crânes d'Homo erectus du site de l'Homme de Yunxian, Quyanhe-kou, Qingqu, Yunxian I et Yunxian II. In: de Lumley H, Li T, editors. Le site de l'Homme de Yunxian, Éditions Recherche sur les Civilisations. CNRS éditions; 2008. p. 381-466.

36. Zhu RX, Potts R, Pan YX, Yao HT, Lu LO, Zhao X. Early evidence of genus Homo in East Asia. J Hum Evol. 2008;55:1075-85.

37. Shen GJ, Gao X, Granger DE. Age of Zhoukoudian Homo erectus determined with ${ }^{26} \mathrm{Al} /{ }^{10} \mathrm{Be}$ burial dating. Nature. 2009:458:198-200.

38. Stiner MC, Barkai R, Gopher A. Cooperative hunting and meat sharing 400200 kya at Quesem cave, Israel. Proc Natl Acad Sci USA. 2009;106:13207-12.

39. Bermúdez de Castro JM, Martinón-Torres M, Gómez-Robles A, Prado-Simón $L$, Carbonell E. New human evidence of the Early Pleistocene settlement of Europe, from Sima del Elefante site (Sierra de Atapuerca, Burgos, Spain). Quat Int. 2010;223-224:431-3.

40. Shen GJ, Fang YS, Bischoff JL, Feng YX, Zhao JX. Mass spectrometric U-series dating of the Chaoxian hominin site at Yinshan, eastern China. Quat Int. 2010;211:24-8.

41. Vialet A, Guipert $G$, Jianing $H$, Xiaobo F, Zune L, Youping W. Homo erectus from the Yunxian and Nankin Chinese sites: anthropological insights using 3D virtual imaging techniques. C R Palevol. 2010;9:331-9. 
42. Wagner GA, Krbetschek M, Degering D, Bahain J-J, Shao Q, Falguères C. Radiometric dating of the type-site for Homo heidelbergensis at Mauer, Germany. Proc Natl Acad Sci USA. 2010;107:19726-30.

43. Bermúdez de Castro JM, Martinón-Torres M, Gómez-Robles A, Prado-Simón L, Martín-Francés L, Lapresa M. Early Pleistocene human mandible from Sima del Elefante (TE) cave site in Sierra de Atapuerca (Spain): a comparative morphological study. J Hum Evol. 2011;61:12-25.

44. Manzi G. On the trail of the genus Homo between archaic and derived morphologies. J Anthropol Sci. 2012;90:99-116.

45. Rosenberg KR, Wu X. A river runs through it: Modern human origins in East Asia. In: Smith FH, Ahern JCM, editors. The origin of modern humans, vol. Chapter 3. 2nd ed. Hoboken: Wiley; 2013. p. 89-121.

46. Shen GJ, Wu XZ, Wang Q, Tu H, Feng YX, Zhao JX. Mass spectrometric Useries dating of Huanglong Cave in Hubei Province, Central China: evidence for early presence of modern humans in eastern Asia. J Hum Evol. 2013;65:162-7.

47. Wu X, Athreya S. A description of the geological context, discrete traits and linear morphometrics of the middle Pleistocene hominin from Dali, Shaanxi Province, China. Am J Phys Anthropol. 2013;150(1):141-57.

48. Antón SC, Potts R, Aiello LC. Evolution of early Homo: an integrated biological perspective. Science. 2014;345(6192):1236828.

49. Shen G, Tu H, Xiao D, Qiu L, Feng YX, Zhao JX. Age of Maba hominin site in southern China: evidence from U-series dating of Southern Branch Cave. Quat Geochronol. 2014;23:56-62.

50. Wu XJ, Trinkaus E. The Xujiayao 14 mandibular ramus and Pleistocene Homo mandibular variation. CR Palevol. 2014;13:333-41.

51. Wu XJ, Crevecoeur I, Liu W, Xing S, Trinkaus E. Temporal labyrinths of eastern Eurasian Pleistocene humans. Proc Natl Acad Sci U S A. 2014;111: 10509-13.

52. Xing S, Martinón-Torres M, de Castro JMB, Zhang Y, Fan X, Zheng L, et al. Middle Pleistocene hominin teeth from Longtan cave, Hexian, China. PLoS ONE. 2014;9(12):e114265.

53. Dennell RW. The Jaramillo Subchron, a geochronological marker horizon in the palaeoanthropological record of China. Qutern Int. 2015;389:241-54.

54. Zhu ZY, Dennell R, Huang WW, Wu Y, Rao ZG, Qiu SF, et al. New dating of the Homo erectus cranium from Lantian (Gongwangling), China. J Hum Evol. 2015;78:144-57.

55. Bermúdez de Castro JM, Martinón-Torres M, Rosell J, Blasco R, Arsuaga JL, Carbonell E. Continuity versus discontinuity of the human settlement of Europe between the late Early Pleistocene and the early Middle Pleistocene. The mandibular evidence. Quat Sci Rev. 2016;153:51-62.

56. Ao H, Liu C-R, Roberts AP, Zhang P, Xu X. An updated age for the Xujiayao hominin from the Nihewan basin North China: implications for Middle Pleistocene human evolution in East Asia. J Hum Evol. 2017;106:54-65.

57. Athreya S, Wu X. A multivariate assessment of the Dali hominin cranium from China: morphological affinities and implications for Pleistocene evolution in East Asia. Am J Phys Anthropol. 2017;164:679-701.

58. Bermúdez de Castro JM, Martinón-Torres M, Martín-Francés L, ModestoMata M, Martínez-de-Pinillos M, García C, Carbonell E. Homo antecessor: The state of the art eighteen years later. Quat Int. 2017:433:22-31.

59. Han F, Bahain J-J, Deng C, Boëda É, Hou Y, Wei G, et al. The earliest evidence of hominid settlement in China: combined electron spin resonance and uranium series (ESR/U-series) dating of mammalian fossil teeth from Longgupo cave. Quat Int. 2017;434:75-83.

60. Huguet R, Vallverdú J, Rodríguez-Álvarez XP, Terradillos-Bernal M, Bargalló A, Lombera-Hermida A, et al. Level TE9c of Sima del Elefante (Sierra de Atapuerca, Spain): A comprehensive approach. Quat Int. 2017;433:278-95.

61. Li ZY, Wu XJ, Zhou LP, Liu W, Gao X, Nian XM, Trinkaus E. Late Pleistocene archaic human crania from Xuchang, China. Science. 2017;355:969-72.

62. Martín-Albaladejo, Martinón-Torres M, García-González R, Arsuaga J-L, Bermúdez de Castro JM. Morphometric analysis of Atapuerca-Sima de los Huesos lower first molars. Quat Int. 2017:433:156-62.

63. Martinón-Torres M, Wu X, de Castro JMB, Xing S, Liu W. Homo sapiens in the Eastern Asian late Pleistocene. Curr Anthropol. 2017;58(Supplement 17): 434-48.

64. Prat S. First hominin settlements out of Africa. Tempo and dispersal mode: review and perspectives. C R Palevol. 2017;127:1-11.

65. Sun XF, Yi S, Lu H, Zhang W. TT-OSL and post-IR IRSL dating of the Dali Man site in Central China. Quat Int. 2017:434:99-106.

66. Duval M, Grün R, Parés JM, Martín-Francés L, Campana I, Rosell J, et al. The first direct ESR dating of a hominin tooth from Atapuerca Gran Dolina TD-6
(Spain) supports the antiquity of Homo antecessor. Quat Geochronol. 2018; 47:120-37.

67. Xing S, Martinón-Torres M, de Castro JMB. The fossil teeth of the Peking Man. 2018. Scientific reports nature s41598-018-20432.

68. Zhu Z, Dennell R, Huang W, Wu Y, Qiu S, Yang S, et al. Hominin occupation of the Chinese loess plateau since about 2.1 million years ago. Nature. 2018; 559:608-12

69. Han F, Shao Q, Bahain J-J, Sun X, Yin G. Coupled ESR and U-series dating of fossil teeth from Yiyuan hominin site, northern China. Quat Geochron. 2019; 49:291-6.

70. Wu XJ, Pei SW, Cai YJ, Tong HW, Li Q, Dong Z, et al. Archaic human remains from Hualongdong, China, and Middle Pleistocene human continuity and variation. Proc Natl Acad Sci U S A. 2019;116:9820-4.

71. de Lumley M-A, Guipert G, de Lumley H, Protopapa N, Pitsios T. Apidima 1 and Apidima 2: Two anteneanderthal skulls in the Peloponnese, Greece. L'Anthropologie. 2020;124:102743.

72. Yang S-X, Deng C-L, Zhu R-X, Petraglia MD. The Paleolithic in the Nihewan Basin, China: evolutionary history of an early to Late Pleistocene record in Eastern Asia. Evol Anthropol. 2020;29:125-42.

73. Welker F, Ramos-Madrigal J, Gutenbrunner P, Mackie M, Tiwary S, Jersie-Christensen RR, et al. The dental proteome of Homo antecessor. Nature. 2020:580:235-8.

74. Arnason U, Xu X, Gullberg A. Comparison between the complete mitochondrial DNA sequence of Homo and the common chimpanzee based on nonchimeric sequences. J Mol Evol. 1996;42:145-52.

75. Green RE, Malaspinas A-S, Krause J, Briggs AW, Johnson PLF, Uhler C, et al. A complete Neandertal mitochondrial genome sequence determined by high-throughput sequencing. Cell. 2008;134:416-26.

76. Krause J, Fu Q, Good JM, Viola B, Shunkov MV, Derevianko AP, et al. The complete mitochondrial DNA genome of an unknown hominin from southern Siberia. Nature. 2010;464:894-7.

77. Malaspinas A-S, Westaway MC, Muller C, Sousa VC, Lao O, Alves I, et al. A genomic history of Aboriginal Australia. Nature. 2016;538:207-14.

78. Jacobs GS, Hudjashow G, Saag L, Kusuma P, Darusallam CC, Lawson DJ, et al. Multiple deeply divergent Denisovan ancestries in Papuans. Cell. 2019; 177:1010-21.

79. Reich D, Patterson N, Kircher M, Delfin F, Nandineni MR, Pugach I, Ko AM, Ko YC, Jinam TA, Phipps ME, et al. Denisova admixture and the first modern human dispersals into Southeast Asia and Oceania. Am J Hum Genet. 2011; 89:516-28.

80. Browning SR, Browning BL, Zhou Y, Tucci S, Akey JM. Analysis of human sequence data reveals two pulses of archaic Denisovan admixture. Cell. 2018;173:53-61.

81. Arnason U, Adegoke JA, Gullberg A, Harley EH, Janke A, Kullberg M. Mitogenomic relationships of placental mammals and molecular estimates of their divergences. Gene. 2008;585:9-12

82. Anderson S, Bankier AT, Barrell BG, de Bruin MHL, Coulson AR, Drouin J, et al. Sequence and organization of the human mitochondrial genome. Nature. 1981;290:457-65

83. McBrearty S, Brooks AS. The revolution that wasn't: a new interpretation of the origin of modern human behaviour. J Hum Evol. 2000;39:453-563.

84. Berger LR, Hawks J, Dirks PHGM, Elliott M, Roberts EM. Homo naledi and Pleistocene hominin evolution in subequatorial Africa. eLife. 2017;6:e24234.

85. Grün R. Direct dating of human fossils. Yearb Phys Anthropol. 2006:49:2-48.

86. Guo Y, Sun C, Luo L, Yang L, Han F, Tu H. ${ }^{26} \mathrm{Al} /{ }^{10} \mathrm{Be}$ burial dating of the middle Pleistocene Yiyuan hominin fossil site, Shandong Province, Northern China. Nat Sci Rep. 2019;9:6961.

87. Ferring $\mathrm{R}$, Oms $\mathrm{O}$, Agustí J, Berna F, Nioradze M, Shelia $\mathrm{T}$, et al. Earliest human occupations at Dmanisi (Georgian Caucasus) dated to 1.85-1.78. Proc Natl Acad Sci USA. 2011;108:10432-6.

88. Lordkipanidze D, de León MSP, Margvelashvili A, Rak Y, Rightmire GP, Vekua A, Zollikofer PE. A complete skull from Dmanisi, Georgia, and the evolutionary biology of early Homo. Science. 2013;342:326-31.

89. Larick RR, Ciochon RL, Zaim Y, Sudijono, Suminto, Rizal Y, Aziz F, et al. Early Pleistocene ${ }^{40} \mathrm{Ar} /{ }^{39} \mathrm{Ar}$ ages for Bapang formation hominins, central Jawa, Indonesia. Proc Natl Acad Sci. 2001;98:4866-71.

90. Zaim Y, Ciochon RL, Polanski JM, Grine FE, Bettis EA III, Rizal Y, et al. New 1.5 million-year-old Homo erectus from Sangrian (Central Java, Indonesia). J Hum Evol. 2011;61:363-76.

91. Matsu'ura S, Kondo M, Danhara T, Sakata S, Iwano H, Hirata T, et al. Age control of the first appearance datum for Javanese Homo erectus in the Sangrian area. Science. 2020;367:210-4. 
92. Hawks J, Elliott M, Schmid P, Churchill SE, de Ruiter DJ, Roberts EM, et al. New fossil remains of Homo naledi from the Lesedi Chamber, South Africa. elife. 2017;6:24232.

93. Dirks PHG, Roberts EM, Hilbert-Wolf H, Kramers JD, Hawks J, Dosseto A, et al. The age of Homo naledi and associated sediments in the Rising Star Cave, South Africa. eLife. 2017;6:e24231.

94. Richter D, Grün R, Johannes-Boyau R, Steele TE, Amani F, Fernandes P, et al. The age of the hominin fossils from Jebel Irhoud, Morocco, and the origins of the middle stone age. Nature. 2017;546:293-6.

95. Hublin J-J, Ben-Ncer A, Bailey SE, Freidline SE, Neubauer S, Skinner MM, et al. New fossils from Jebel Irhoud, Morocco and the pan-African origin of Homo sapiens. Nature. 2017;546:289-92.

96. Smith TM, Tafforeau P, Reid DJ, Grün R, Eggins S, Boutakiout M, Hublin J-J. Earliest evidence of modern human life history in North African early Homo sapiens. Proc Natl Acad Sci U S A. 2007:104:6128-33.

97. Harvati K, Röding C, Bosman AM, Karakostis FA, Grün R, Stringer C, et al. Apidima cave fossils provide earliest evidence of Homo sapiens in Eurasia. Nature. 2019. https://doi.org/10.1038/s41586.

98. Rosas A, Bastir M. An assessment of the late Middle Pleistocene occipital from Apidima 1 skull (Greece). L'anthropologie. 2020;124:10275.

99. Galway-Witham J, Stringer C. How did Homo sapiens evolve? Science. 2018; 360:1296-8.

100. Bae CJ, Douka K, Petraglia MD. On the origin of modern humans: Asian perspectives. Science. 2018;358:eaai9067.

101. Petit JR, Jouzel J, Raynaud D, Barkov NI, Barnola J-M, Basile I, et al. Climate and atmospheric history of the past 420,000 years from the Vostok ice core, Antarctica. Nature. 1999;399:429-36.

102. Parrenin F, Barnola J-M, Beer J, Blunier T, Castellano E, Chappellaz, et al. The EDC3 chronology for the EPICA Dome ice core. Clim Past. 2007;3:485-97.

103. Lang N, Wolff EW. Interglacial and glacial variability from the last $800 \mathrm{ka}$ in marine, ice and terrestrial archives. Clim Past. 2011;7:361-80.

104. Ingman M, Kaessmann H, Pääbo S, Gyllensten U. Mitochondrial genome variation and the origin of modern humans. Nature. 2000;408:708-13.

105. Hammer MF, Woerner AE, Mendez FL, Watkins JC, Wall JD. Genetic evidence for archaic admixture in Africa. Proc Natl Acad Sci U S A. 2011;108:15123-8.

106. Lachance J, Vernot B, Elbers CC, Ferwerda B, Froment A, Bodo J-M, et al. Evolutionary history and adaptation from high-coverage whole-genome sequences of diverse African hunter-gatherers. Cell. 2012;150:457-69.

107. Hsieh PH, Woerner AE, Wall JD, Lachance J, Tishkoff SA, Gutekunst RN, Hammer MF. Model-based analyses of whole-genome data reveal a complex evolutionary history involving archaic introgression in Central African pygmies. Genome Res. 2016;26:291-300.

108. Krause J, Orlando L, Serre D, Bence V, Prüfer K, Richards MP, et al. Neanderthals in Central Asia and Siberia. Nature. 2007:449:902-4.

109. Reich D, Green RE, Kircher M, Krause J, Patterson N, Durand EY, Viola B, Briggs AW, Stenzel U, Johnson PLF, et al. Genetic history of an archaic hominin group from Denisova Cave in Siberia. Nature. 2010;468:1053-60.

110. Sankararaman S, Mallick S, Patterson N, Reich D. The combined landscape of Denisovan and Neanderthal ancestry in present-day humans. Curr Biol. 2016:26:1241-7.

111. Vernot B, Tucci S, Kelso J, Schraiber JG, Wolf AB, Gittelman RM, Dannemann M, Grote S, McCoy RC, Norton H, et al. Excavating Neandertal and Denisovan DNA from the genomes of Melanesian individuals. Science. 2016; 352:235-9.

112. Tjio JH, Levan A. The chromosome number of man. Hereditas. 1956;42:1-6.

113. Arnason A. 50 years after - examination of some circumstances around the establishment of the correct chromosome number of man. Hereditas. 2006; 143:202-11.

114. Darlington CD, Haque A. Chromosomes of monkeys and men. Nature. 1955; 175:32.

\section{Publisher's Note}

Springer Nature remains neutral with regard to jurisdictional claims in published maps and institutional affiliations.

Ready to submit your research? Choose BMC and benefit from:

- fast, convenient online submission

- thorough peer review by experienced researchers in your field

- rapid publication on acceptance

- support for research data, including large and complex data types

- gold Open Access which fosters wider collaboration and increased citations

- maximum visibility for your research: over $100 \mathrm{M}$ website views per year

At BMC, research is always in progress.

Learn more biomedcentral.com/submissions 